\title{
FLORISTIC ANALYSIS OF THREATENED MEDICINAL PLANTS ON THE TERRITORY OF BREDHIK RESERVE, SHARR MOUNTAIN, KOSOVO
}

\author{
Avdyl Bajrami ${ }^{1 *}$, Erta Dodona ${ }^{1}$, Haxhi Halilaj ${ }^{1}$, Xhavit Mala ${ }^{2}$ \\ ${ }^{1 *}$ Agricultural University of Tirana, Faculty of Agriculture and Environment, Albania; \\ ${ }^{2}$ Ministry of Environment and Spatial Planning -DAPK "Sharr Mountain”, Kosovo; \\ *Corresponding Author Avdyl Bajrami, e-mail:bajramiavdyl@gmail.com;
}

Received September 2020; Accepted October 2020; Published November 2020;

DOI: https://doi.org/10.31407/ijees10.427

\begin{abstract}
This study was carried out to identify the medicinal plants of conservation status on the territory of Bredhik Strict Nature Reserve (Sharr Mountain, Kosovo). Biodiversity of medicinal plants listed in this study represented by 91 taxa that belong to 43 families and 74 genera. Rosaceae and Asteraceae, with 11 and 10 species respectively, are the families by the high number of threatened species. The main genera were Plantago, Prunus and Salix with 3 species each. The species with conservation status by European Red List of Medicinal Plants are 68 species, while in IUCN Red List are included 51 taxa. Hemicryptophytes and perennial herbaceous plants with 38 species and 44 species were dominant on the plants that were the subject of this research. The number of relics species is significant, 20 species (21.98\% of the total species number), and therefore area of study has the highest conservation value.
\end{abstract}

Keywords: Medicinal plants, Threatened plants, Biological types, Relict species. 